Because this photoreceptor is known to occur in the fruitfly Drosophila, Charlotte Helfrich-Förster of the University of Regensburg in Germany and her colleagues subjected flies to applied magnetic fields under both red and blue light. The static magnetic fields slowed the flies' circadian clocks, but only in the presence of blue light. Flies under red light showed no response. Mutant flies overexpressing cryptochrome had an even more pronounced response.

Thus the authors suggest the fly could be a model system for cryptochrome-dependent magnetic sensitivity - which may be used, for example, by migratory birds for compass orientation.

\section{COGNITIVE PSYCHOLOGY}

\section{Bilingual baby talk}

Proc. Natl Acad. Sci. USA 106, 6556-6560 (2009)

How do babies in bilingual households cope with life in two languages? New work suggests that the challenging environment may enhance infants' cognitive abilities before they even begin to speak.

Ágnes Melinda Kovács and Jacques Mehler of the International School for Advanced Studies in Trieste, Italy, trained 40 infants aged 7 months from monolingual or bilingual households to anticipate a visual reward after a spoken cue. When the visual reward - a picture of a puppet - was shifted from one side of the computer screen to the other, bilingual infants were better able to adapt to the change and shift their gaze.

The research indicates an enhancement in executive function, a cognitive control mechanism that may aid the simultaneous acquisition of two languages.

\section{CLIMATE MODELLING}

\section{Soot and warming}

Nature Geosci. 2, 294-300 (2009)

Aerosols such as soot and sulphates have a significant influence on climate at northern mid-latitudes and in the Arctic.

Drew Shindell and Greg Faluvegi of NASA's Goddard Institute for Space Studies in New York quantified regional climate sensitivity to carbon dioxide, ozone, sulphate and black carbon, or soot, using a coupled ocean-atmosphere climate model.

Comparing their results to observed twentieth-century temperature trends, they calculated that greenhouse gases and ozone alone cannot explain rapid warming in the north. Declining levels of sulphates, which cool temperatures by reflecting sunlight, and rising levels of soot, which absorb solar radiation, probably account for as much as $45 \%$ of the observed Arctic warming over the past three decades, they say.

\section{EVOLUTION}

\section{Bitter apple}

Proc. R. Soc. B doi:10.1098/rspb.2009.0355 (2009) In spring, aphid larvae emerge from eggs laid on host plants and head for the leaves to feed. But, for at least one aphid species (Dysaphis plantaginea), those whose parents laid eggs on apple tree (Malus pumila) hosts with red leaves in the autumn do less well than those laid on trees with yellow or green leaves. Marco Archetti of the University of Oxford, UK, says that this supports the theory that red leaves serve as an 'honest' signal to insects warning against such factors as robust chemical defences. Domesticated apple trees were selected for nice fruit, not insect resistance, and as such should not advertise defences they have not retained. Accordingly, Archetti finds that domesticated apples rarely have red leaves in autumn. There might even be a direct trade-off; red-leaved trees make smaller, less palatable apples.

\section{MICROBIOLOGY}

\section{Colony collapse cured?}

Environ. Microbiol. Rep. 1, 110-113 (2009) Bee-keepers and the crop producers they serve have been plagued worldwide by the mysterious disappearance of the European honeybee Apis mellifera. Various causes have been touted for this 'colony collapse disorder', including pesticide use, viruses and mites. Mariano Higes of the Regional Apiculture Center in Marchamalo, Spain, and his collaborators had previously fingered a gut-infecting fungus, Nosema ceranae, as a suspect. More recently, while studying two embattled Spanish apiaries 750 kilometres apart, they found N. ceranae to be the only likely suspect. Moreover, at these apiaries, the fungicide fumagillin halted colony collapse and cleared the infection from existing colonies. Although these results are promising, N. ceranae may not be to blame for all cases of colony collapse.

\section{JOURNAL CLUB}

\section{Dave Featherstone \\ University of Illinois at Chicago}

\section{A neuroscientist argues for a broader approach to brain mapping.}

Efforts to map all of the connections between the brain's neurons - known as synapses - are gathering momentum. Neural 'wiring diagrams' have even garnered a label: the 'connectome'. But I worry that the connectome will be a waste of time and money, and that we'll eventually need to redo the whole thing.

Why am I so negative? Although the connectome is ambitious, it's not ambitious enough. As currently envisioned, it ignores most brain cells as well as possible functional connections between those cells.

Although you wouldn't know it from all the attention they receive, neurons are a relatively minor type of brain cell, making up less than $10 \%$ of the human brain. And synapses between neurons make up only a small subset of all possible functional connections in the brain. Most brain cells are actually glia, which have long been neglected by neuroscientists owing to their lack of electrical signalling. But glia are increasingly being recognized as having important roles in brain function.

For example, consider the recent study of adenosine and sleep led by Philip Haydon and Marcos Frank at the University of Pennsylvania in Philadelphia (M. M. Halassa et al. Neuron 61, 213-219; 2009). Adenosine binds to receptors on neurons, thereby regulating neuronal signalling. Interestingly, adenosine seems to represent 'sleepiness': it accumulates during wakefulness and dissipates during sleep. Where does it come from? It is generated from adenosine triphosphate (ATP), which is secreted by astrocytes - a major type of glia.

Therefore, if we want to map the functional brain connections controlling sleep, we need to include glia and the extracellular space between glia and neurons. If we're going to understand brain function by mapping the brain, we need to include most of the brain in our map.

Discuss this paper at http://blogs. nature.com/nature/journalclub 